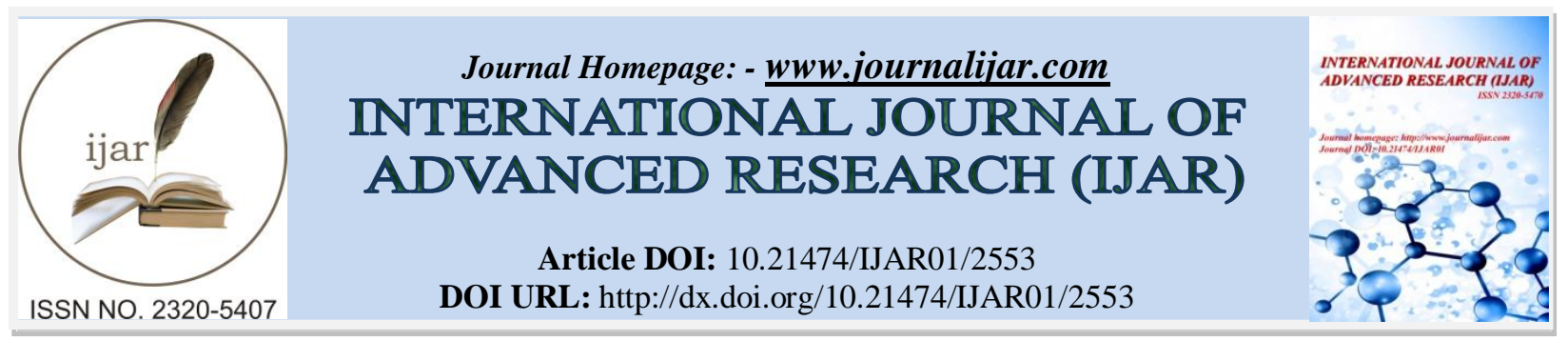

RESEARCH ARTICLE

\title{
A CASE OF UNUSUAL PRESENTATION OF MASSIVE SUBMACULAR HEMORRHAGE
}

khalid Omair Alshehri, Saad Waheeb and Abdulaziz Alshehri.

Department of Ophthalmology - King Faisal Specialist hospital, Jeddah, Saudi Arabia.

\section{Manuscript Info}

Manuscript History

Received: 27 October 2016

Final Accepted: 25 November 2016

Published: December 2016

Key words:-

submacular hemorrhage, tissue

plasminogen activator, sulfur

hexafluoride gas

\section{Abstract}

Eighty -one years old female patient admitted to Ophthalmology department, with poor vision in her right eye. She had wet age related macular degeneration (ARMD) and glaucoma in both eyes and she was on xalatan. On examination, right eye showed posterior chamber intraocular lens (Pciol) in place, retina showed fibrovascular pigment epitheleal detachment, fovea dry, shifting subretinal fluid with some subretinal bleeding superior to the fovea whereas left eye lens showed nuclear sclerosis (NS) 3+, retina showed macular drusen, fibrovascular pigment epithelial detachment with minimal SRF and flat retina. The diagnosis was submacular hemorrhage. The patient was treated through inject lucentis, TPA and SF6 gas intravitreal under sedation in the right eye. On follow-up, the patient showed great improvement in the form of decrease in subretinal fluid and the hemorrhages. In conclusion, intravitreal injection of lucentis, TPA and SF6 gas lead to improvement of cases presented with massive submacular hemorrhage.

Copy Right, IJAR, 2016,. All rights reserved.

\section{Introduction:-}

Submacular hemorrhage is a condition resulted from choroidal and retinal vessel abnormalities frequently originating form of choroidal neovascular membrane secondary to age-related macular degeneration. Other conditions such as myopia, trauma, angioid streaks and ocular histoplasmosis can lead to submacular hemorrhage. ${ }^{1-3}$ A small, thin submacular hemorrhage can often be noticed, while severe massive submacular hemorrhages often have a poor prognosis unless treated. ${ }^{1,4}$

Patients with submacular hemorrhage usually have a progressive decline in their vision. ${ }^{3}$ As a result of severe, progressive vision loss, several treatment strategies have been tried aimed at the removal or displacement of the hemorrhage. Some techniques are office-based, while others are performed in the operating room.

\section{Case report:-}

Eighty -one years old female patient admitted Ophthalmology department, with poor vision in her right eye. She had wet age related macular degeneration (ARMD) and glaucoma in both eyes and she was on xalatan. She has huge subretinal bleeding occupying the entire posterior pole (more than 1000 micron in thickness). She underwent pars plane vitrectomy one month ago with subretinal TPA injection and SF6 gas was injected. NO history of diabetes mellitus or hypertension. 
On examination, visual acuity showed that in the right eye, the patient can count finger near face, lids were within normal limits, conjunctiva was quite, cornea was clear, anterior chamber was deep and quite, Lens showed that posterior chamber intraocular lens (Pciol) in place, retina showed fibrovascular pigment epitheleal detachment, fovea dry, shifting subretinal fluid with some subretinal bleeding superior to the fovea (figure 1) and optic nerve showed advanced cupping.

In the left eye, visual acuity was 20/130, lids were within normal limits, conjunctiva was quite, cornea was clear, anterior chamber was deep and quite, Lens showed nuclear sclerosis (NS) 3+, retina showed macular drusen, fibrovascular pigment epithelial detachment with minimal SRF, flat retina and optic nerve showed advanced cupping.

Intraocular pressure was 17 and $15 \mathrm{mmHg}$ in the right and left eye, respectively.

OCT before the treatment, showed multiple areas of subretinal fluid correlated to the hemorrhage and after the treatment showed resolution of the subretinal fluid. (Figures $2 a$ and $2 b$ )

The patient was treated through inject lucentis, tissue plasminogen activator (TPA) and sulfur hexafluoride gas (SF6) intravitreal under sedation in the right eye. On follow-up, the patiens showed great improvement in the form of decrease in subretinal fluid and some resolution of the haemorrahes as seen in figure 2

In conclusion, intravitreal injection of lucentis, tissue plasminogen activator (TPA) and sulfur hexafluoride gas (SF6) lead to improvement of cases presented with massive submacular hemorrhage.

SF6 gas.

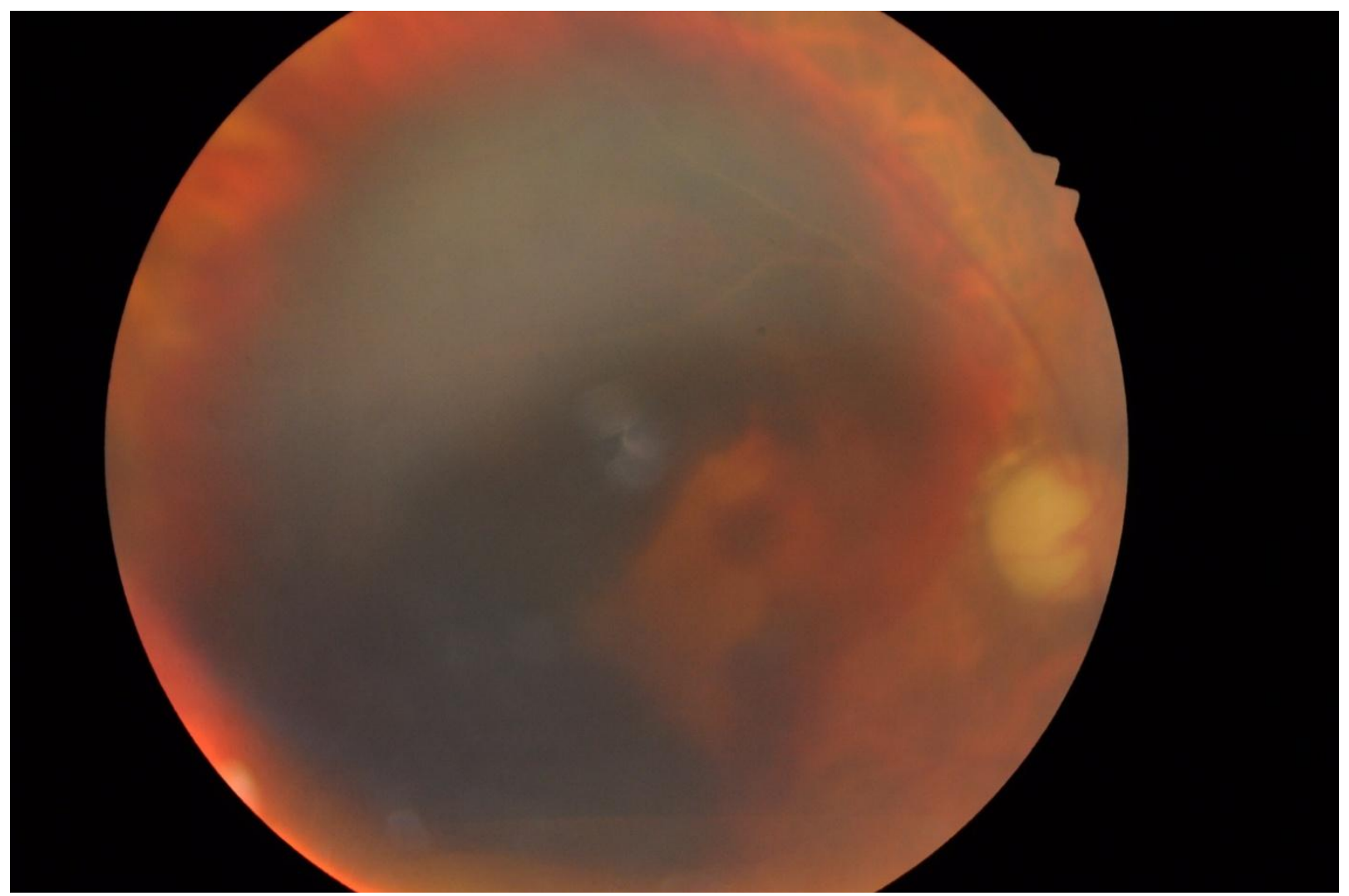

Figure 1:- Fundus examination at presentation. 


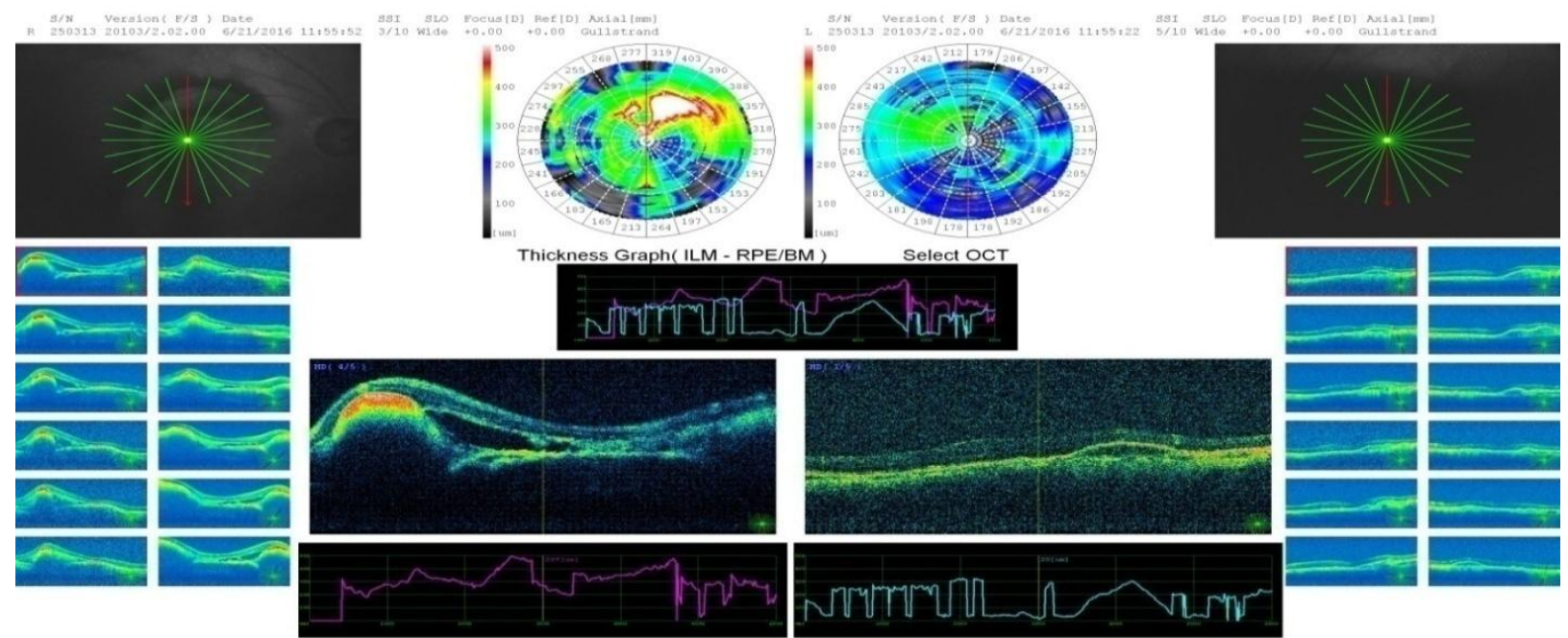

Figure 2a:-

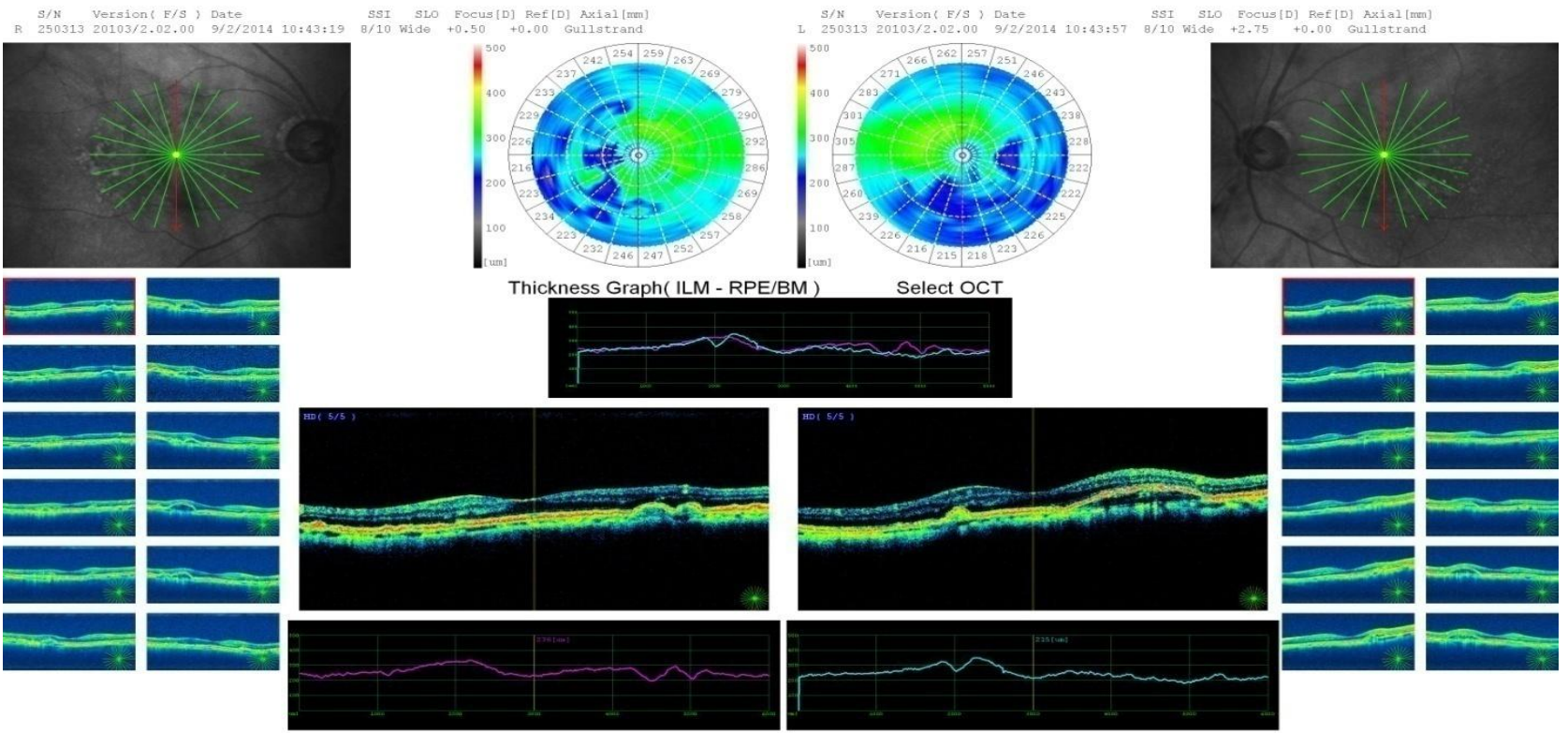

Figure 2:- (figure 2a) showed the OCT at presentation with subretinal fluid which is correlated to the hemorrhage and (figure 2b) showed OCT after the treatment with lucentis, TPA and SF6 gas and it shows resolution of the subretinal fluid. 


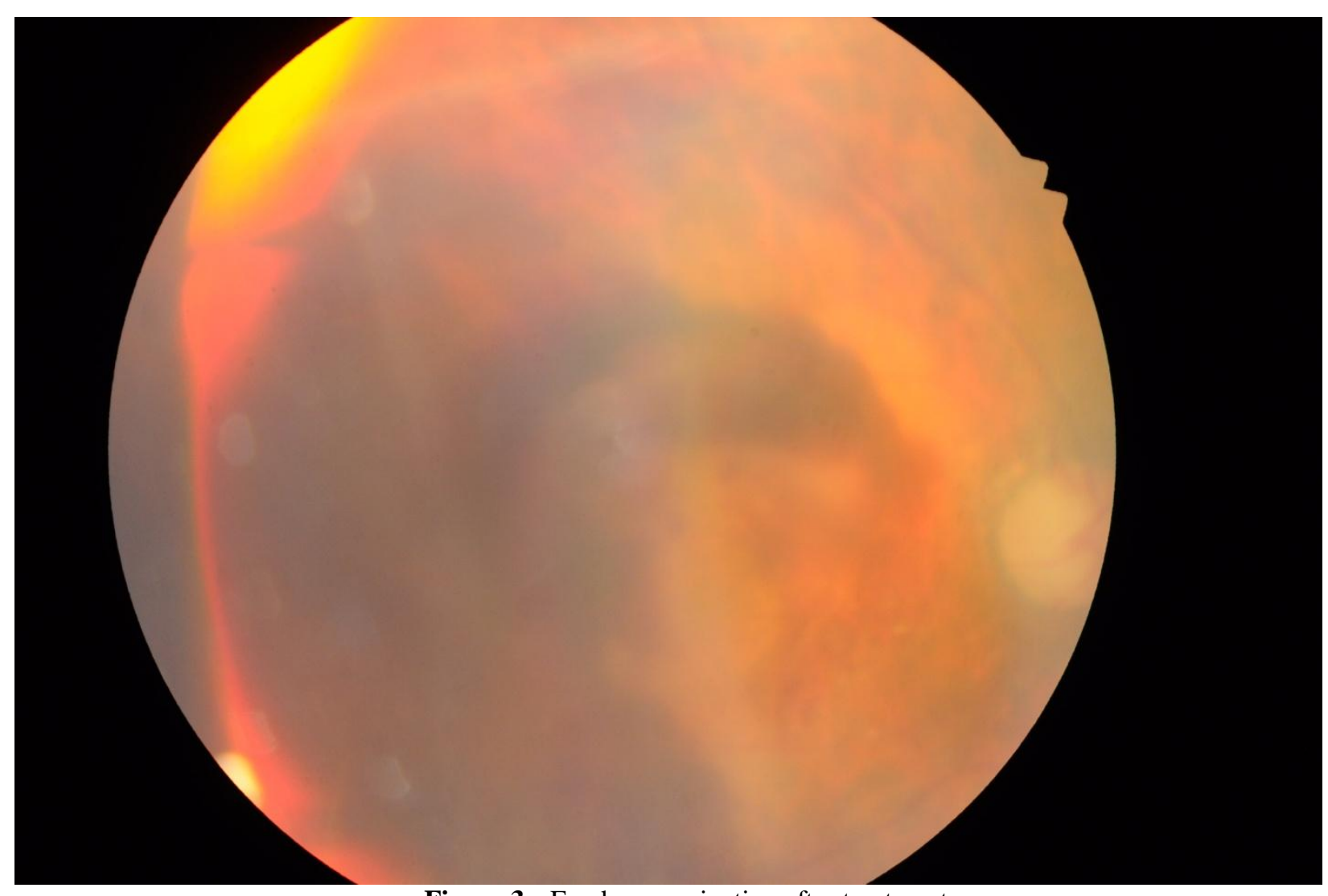

Figure 3:- Fundus examination after treatment.

\section{Discussion:-}

A huge subretinal bleeding occupying the entire posterior pole of eighty -one years old female patient was displaced successfully using intravitreal injection of lucentis, tissue plasminogen activator (TPA) and sulfur hexafluoride gas (SF6).

In Japan, a 13-year-old boy presented with a traumatic thick submacular hemorrhage in his left eye and the patient was able only to perceive hand motions. He was treated through vitrectomy, subretinal injection of 4,000 IU TPA $(6.9 \mu \mathrm{g})$ and air tamponade. Most of the submacular hemorrhage had moved to the inferior periphery, one day after surgery. Cataract was formed after one month from surgery as well as thin remnants of the submacular hemorrhage and juxtafoveal choroidal rupture happened. A second surgery was performed for cataract and injected bevacizumab intravitreally to prevent the development of choroidal neovascularization. Two months after the second surgery, the submacular hemorrhage had totally disappeared and the patient had a visual acuity of $20 / 40 .{ }^{5}$

Also, another case of traumatic submacular hemorrhage in which the authors injected TPA subretinally, ${ }^{6}$ which has generally been injected subretinally to displace submacular hemorrhage due to age related macular degeneration Since TPA has been reported to cause retinal toxicity, such as a decreased amplitude in electroretinography and atrophy of photoreceptors, ${ }^{(7,8)}$ it is important to carefully consider the dose of TPA used. follow-up will be needed to monitor any retinal toxicity due to TPA in the present case.

Intravitreal injection of bevacizumab was reported in one case to absorb a submacular hemorrhage due to traumatic choroidal rupture. ${ }^{(9)}$ The authors reported that the anti-inflammatory effect of the bevacizumab drug promoted the absorption of the submacular hemorrhage. In the present case, choroidal neovascularization has not been seen so far in, however, longer follow-up is needed to monitor for its existence.

In this case, we chose intravitreal injection of lucentis, tissue plasminogen activator (TPA) and sulfur hexafluoride gas (SF6) because of the old age of the case and also because the submacular hemorrhage was very massive thick. 
Furthermore, it has been approved that the subretinal injection of TPA is efficient for adult massive submacular hemorrhage. ${ }^{(10)}$

In summary, lucentis, tissue plasminogen activator (TPA) and sulfur hexafluoride gas (SF6) may be a promising strategy for treating massive submacular hemorrhage in old patients. However, this report describes only a single case, with a relatively short follow-up period so far, and randomized controlled clinical studies involving a larger number of patients will be recommended to determine the impact of this management of massive subretinal hemorrhage in elderly patients.

\section{References:-}

1. Shultz RW, Bakri SJ. Treatment for submacular hemorrhage associated with neovascular age-related macular degeneration. Semin Ophthalmol 2011;26(6):361-71.

2. Skaf AR, Mahmoud T. Surgical treatment of age-related macular degeneration. Semin Ophthalmol 2011;26(3):181-91.

3. Avery RL, Fekrat S, Hawkins BS, Bressler NM. Natural history of subfoveal subretinal hemorrhage in agerelated macular degeneration. Retina 1996;16:183-9.

4. Doi S, Kimura S, Morizane Y, Shiode Y, Hosokawa M, Hirano M, et al. Successful displacement of a traumatic submacular hemorrhage in a 13-year-old boy treated by vitrectomy, subretinal injection of tissue plasminogen activator and intravitreal air tamponade: a case report. BMC Ophthalmol. 2015; 15: 94.

5. Doi S, Kimura S, Morizane Y, Shiode Y, Hosokawa M, Hirano M, et al. Successful displacement of a traumatic submacular hemorrhage in a 13-year-old boy treated by vitrectomy, subretinal injection of tissue plasminogen activator and intravitreal air tamponade: a case report. BMC Ophthalmology (2015) 15:94

6. Hillenkamp J, Surguch V, Framme C, Gabel V-P, Sachs HG. Management of submacular hemorrhage with intravitreal versus subretinal injection of recombinant tissue plasminogen activator. Graefes Arch Clin Exp Ophthalmol. 2010;248:5-11.

7. Ament CS, Zacks DN, Lane AM, Krzystolik M, D'Amico DJ, Mukai S, et al. Predictors of visual outcome and choroidal neovascular membrane formation after traumatic choroidal rupture. Arch Ophthalmol. 2006;124:95766.

8. Secrétan M, Sickenberg M, Zografos L, Piguet B. Morphometric characteristics of traumatic choroidal ruptures associated with neovascularization. Retina. 1998;18:62-6.

9. Abdul-Salim I, Embong Z, Khairy-Shamel S-T, Raja-Azmi M-N. Intravitreal ranibizumab in treating extensive traumatic submacular hemorrhage. Clin Ophthalmol. 2013;7:703-6.

10. Kimura S, Morizane Y, Hosokawa M, Shiode Y, Kawata T, Doi S, et al. Submacular hemorrhage in polypoidal choroidal vasculopathy treated by vitrectomy and subretinal tissue plasminogen activator. Am J Ophthalmol. 2014;159:683-9. 